\title{
Paenibacillus massiliensis sp. nov., Paenibacillus sanguinis sp. nov. and Paenibacillus timonensis sp. nov., isolated from blood cultures
}

\author{
Véronique Roux and Didier Raoult \\ Laboratoire de Bactériologie-Virologie, Hôpital de la Timone, CNRS UMR 6020, IFR48, \\ Boulevard Jean Moulin, 13385 Marseille Cedex 05, France
}

Correspondence

Didier Raoult

didier.raoult@

medecine.univ-mrs.fr

\begin{abstract}
Gram-positive, spore-forming rods were isolated from blood cultures of three different patients. Based on phylogenetic analyses, these strains were placed within the Paenibacillus cluster and specific phenotypic characteristics for each strain were described. Levels of 16S rRNA gene sequence similarity between existing Paenibacillus species and the three novel strains $2301065^{\top}$, $2301032^{\top}$ and $2301083^{\top}$ were $87 \cdot 6-94 \cdot 4,88 \cdot 5-95 \cdot 4$ and $87 \cdot 5-96 \cdot 0 \%$, respectively, and anteiso-branched $\mathrm{C}_{15 \text { : } 0}$ was the major fatty acid. On the basis of phenotypic data and phylogenetic inference, it is proposed that these strains should be designated Paenibacillus massiliensis sp. nov., Paenibacillus sanguinis sp. nov. and Paenibacillus timonensis sp. nov. The type strains are respectively strain $2301065^{\top}\left(=\right.$ CIP $107939^{\top}=$ CCUG $\left.48215^{\top}\right)$, strain $2301083^{\top}$ $\left(=\mathrm{CIP} 107938^{\top}=\right.$ CCUG $\left.48214^{\top}\right)$ and strain $2301032^{\top}\left(=\operatorname{CIP} 108005^{\top}=\right.$ CCUG $\left.48216^{\top}\right)$.
\end{abstract}

Gene comparison studies have shown that $16 \mathrm{~S}$ rRNA is highly conserved within a species and among species of the same genus. Since the pioneering work of Woese (1987), identification and phylogenetic analysis of many bacteria have been performed and have allowed for the classification of non-cultivable organisms and organisms with ambiguous biochemical profiles. Based on phylogenetic studies using the 16S rRNA gene, the so-called rRNA group 3 bacilli were separated to form the novel genus Paenibacillus (Ash et al., 1993); several novel species of Paenibacillus have recently been described (Aguilera et al., 2001; Elo et al., 2001; Meehan et al., 2001; Dasman et al., 2002; Takeda et al., 2002; Yoon et al., 2003).

Paenibacillus species have been isolated from human biological samples and the possibility that these bacteria may cause human infection has been considered. Prosthetic hip infection and endophthalmitis caused by Paenibacillus alvei (Antonello \& Weinstein, 1989; Reboli et al., 1989), brain abscess, catheter-associated infection and wound infection due to Paenibacillus macerans were reported (Bert et al., 1995; Barrero et al., 1996). Pseudobacteraemia due to Paenibacillus may also result from contamination of gloves, alcohol swabs, intravenous catheters or blood culture media

Published online ahead of print on 9 January 2004 as DOI 10.1099/ ijs.0.02954-0.

The GenBank/EMBL/DDBJ accession numbers for the 16S rRNA gene sequence of $P$. massiliensis strain $2301065^{\top}, P$. sanguinis strain $2301083^{\top}$ and $P$. timonensis strain $2301032^{\top}$ are respectively AY323608, AY323609 and AY323610 (clone 1), AY323611 (clone 2) and $A Y 323612$ (clone 3).
(CDC, 1974; Berger, 1983; York, 1990; Noskin et al., 2001; Teng et al., 2003).

The data presented in this paper describe three novel Paenibacillus species, two of which are related closely to Paenibacillus macerans (Ash et al., 1993; Heyndrickx et al., 1996); the third can be grouped with Paenibacillus illinoisensis (Shida et al., 1997). These species were initially isolated from blood culture samples of patients suffering from carcinoma, chronic interstitial nephropathy or leukaemia.

\section{Isolation and characterization of strains}

Reference strains were obtained from the Pasteur Institute (Paris, France).

Paenibacillus macerans strain CIP $66.19^{\mathrm{T}}$, Paenibacillus pabuli strain CIP $103119^{\mathrm{T}}$ and Paenibacillus polymyxa strain CIP $66.22^{\mathrm{T}}$, and clinical strains $2301083^{\mathrm{T}}\left(=\mathrm{CIP} 107938^{\mathrm{T}}=\right.$ CCUG $\left.48214^{\mathrm{T}}\right), 2301065^{\mathrm{T}}\left(=\mathrm{CIP} 107939^{\mathrm{T}}=\mathrm{CCUG} 48215^{\mathrm{T}}\right)$ and $2301032^{\mathrm{T}}\left(=\mathrm{CIP} 108005^{\mathrm{T}}=\right.$ CCUG $48216^{\mathrm{T}}$ ), were isolated on Columbia blood agar plates (Oxoid) from blood samples in the bacteriology laboratory of the Timone hospital.

In October 1999, cervical adenopathy was detected in a 49year-old man. Diagnosis of epidermoid carcinoma of the oropharynx was established and chemotherapy and radiotherapy were performed. In November 2002, at the time of hospitalization for chemotherapy, the patient was afebrile, but a blood sample was collected from which Gram-positive rods were isolated (strain $2301083^{\mathrm{T}}$ ).

In March 2001, acute lymphoblastic leukaemia was diagnosed 
in a 13-year-old boy who received chemotherapy. In August 2001, allograft with compatible stem cells of umbilical blood was performed. At this time, cutaneous and hepatic graft versus host disease was noted. In October 2002, he was hospitalized with fever $\left(38.5^{\circ} \mathrm{C}\right)$ and neutropenia. Blood samples were obtained and Gram-positive rods $\left(\right.$ strain $\left.2301065^{\mathrm{T}}\right)$ were isolated from one of three blood samples.

In October 2002, strain $2301032^{\mathrm{T}}$ was isolated from a 75year-old woman who presented with chronic interstitial nephropathy that required haemodialysis from February 1989. At the time of the bacterial isolation, she was apyretic, but presented with loose cough and sputum.

All of the isolated bacteria were Gram-positive rods; their size was determined by transmission electron microscopy using cells from a $48 \mathrm{~h}$ culture. Bacterial suspension was pre-fixed in $5 \%(\mathrm{v} / \mathrm{v})$ glutaraldehyde in phosphate buffer (Gibco) for at least $1 \mathrm{~h}$ at room temperature, washed in the same buffer and stained with $1 \%(\mathrm{w} / \mathrm{v})$ phosphotungstic acid. Sporulation was studied by the same method. After the pre-fixation step, specimens were post-fixed with $4 \%$ (w/v) osmium tetroxide for $1 \mathrm{~h}$, dehydrated by using a graded series of acetone, transferred to $100 \%$ acetone and embedded in Epon 812 (Fluka) substitute. Thin sections were cut with a diamond knife on a Leica Ultracut VCT microtome and stained with uranyl acetate and lead citrate. The grids were examined on a MORGANI 268 D (Philips) transmission electron microscope at an operating voltage of $60 \mathrm{kV}$. Bacteria of strain $2301065^{\mathrm{T}}$ were $0.5 \mu \mathrm{m}$ wide and $2 \cdot 0-4 \cdot 0 \mu \mathrm{m}$ long. They formed translucent, flat colonies of beige colour after $24 \mathrm{~h}$ incubation at $30^{\circ} \mathrm{C}$. Cells of strain $2301083^{\mathrm{T}}$ were $0 \cdot 5 \mu \mathrm{m}$ wide and $2 \cdot 0-3 \cdot 0 \mu \mathrm{m}$ long, forming greyish colonies that were translucent, shiny, $1 \mathrm{~mm}$ in diameter after $24 \mathrm{~h}$ incubation at $30^{\circ} \mathrm{C}$, circular and regularly shaped. Isolated bacteria of strain $2301032^{\mathrm{T}}$ were rods of $0.5 \mu \mathrm{m}$ width and $2.0 \mu \mathrm{m}$ length. Colonies were greyish, translucent, shiny, $1.5 \mathrm{~mm}$ in diameter, regularly shaped and low convex. Presence of spores was studied after 8 days growth at room temperature and was reported for the three isolates. Terminal or subterminal ellipsoidal spores were observed in swollen sporangia.

Growth temperatures tested were $30,37,44$ and $50^{\circ} \mathrm{C}$, the optimum being $30-37^{\circ} \mathrm{C}$. Catalase activity was determined with the ID colour catalase test kit (bioMérieux). Oxidase activity was assayed by applying the cells to moistened discs that were impregnated with dimethyl-p-phenylene diamine (bioMérieux). Mobility was determined by light microscopy. An anaerobic atmosphere was created by using GENbag anaer (bioMérieux). Acid production from 49 carbon sources was tested at $30^{\circ} \mathrm{C}$ under anaerobic conditions with an API 50CH kit combined with API 50CHB/E medium (bioMérieux). Other tests were completed with API $20 \mathrm{E}$ (bioMérieux). Tolerance to $\mathrm{NaCl}$ was measured in trypticase soy broth that contained $1-5 \%(\mathrm{w} / \mathrm{v}) \mathrm{NaCl}$. All three strains were motile by means of peritrichous flagella and facultatively anaerobic. With the exception of strain $2301083^{\mathrm{T}}$, the isolates grew at $50^{\circ} \mathrm{C}$. None of the strains showed haemolytic activity on Columbia blood agar. $\mathrm{ADH}, \mathrm{LDC}, \mathrm{ODC}, \mathrm{CIT}, \mathrm{H}_{2} \mathrm{~S}, \mathrm{URE}, \mathrm{TDA}$ and IND tests in API $20 \mathrm{E}$ strips were negative for all isolates tested. The three strains grew in the presence of $3 \% \mathrm{NaCl}$, but strain $2301065^{\mathrm{T}}$ also grew in the presence of $5 \% \mathrm{NaCl}$. Diagnostic traits are specified in Table 1.

Preparation and determination of cellular fatty acids followed the procedures given for the Sherlock Microbial Identification system (MIDI). The major fatty acids found

Table 1. Diagnostic traits of the different species and isolates tested in this study

Strains: 1 , P. polymyxa CIP $66.22^{\mathrm{T}} ; 2$, P. pabuli CIP $103119^{\mathrm{T}} ; 3, P$. macerans CIP $66.19^{\mathrm{T}}$; 5, P. massiliensis $2301065^{\mathrm{T}} ; 4$, P. sanguinis $2301083^{\mathrm{T}}$; 6, P. timonensis $2301032^{\mathrm{T}}$. Mobility was positive for all strains.

\begin{tabular}{|c|c|c|c|c|c|c|}
\hline Characteristic & 1 & 2 & 3 & 4 & 5 & 6 \\
\hline Catalase & + & + & + & + & - & + \\
\hline Oxidase & - & + & + & - & - & + \\
\hline Growth at $50^{\circ} \mathrm{C}$ & - & - & + & + & - & + \\
\hline Growth at $44^{\circ} \mathrm{C}$ & + & - & + & + & + & + \\
\hline Anaerobic growth & - & + & + & + & + & + \\
\hline Spore presence & + & + & - & + & + & + \\
\hline Haemolysis & + & + & - & - & - & - \\
\hline Growth in presence of $5 \% \mathrm{NaCl}$ & - & - & - & + & - & - \\
\hline Nitrate reduction & + & + & + & + & - & $\mathrm{W}+{ }^{*}$ \\
\hline Voges-Proskauer test & - & - & + & - & - & - \\
\hline Gelatin liquefaction & + & - & - & - & - & - \\
\hline \multicolumn{7}{|l|}{ Acid production from: } \\
\hline Glycerol & + & + & + & + & - & - \\
\hline D-Arabinose & - & - & + & - & - & - \\
\hline Ribose & + & + & + & + & - & - \\
\hline D-Xylose & + & + & + & - & + & + \\
\hline Methyl $\beta$-D-xyloside & + & + & + & - & + & - \\
\hline Glucose & + & + & + & + & - & + \\
\hline Mannose & + & + & + & + & - & + \\
\hline Rhamnose & - & - & + & - & - & - \\
\hline Mannitol & + & + & + & + & + & - \\
\hline Methyl $\alpha$-D-glucoside & + & + & + & - & + & + \\
\hline$N$-Acetylglucosamine & - & + & - & - & + & + \\
\hline Sucrose & + & + & + & + & + & - \\
\hline Inulin & - & + & + & - & + & - \\
\hline Melezitose & - & + & + & - & + & - \\
\hline Raffinose & + & + & + & + & + & - \\
\hline Starch & + & + & + & + & - & + \\
\hline Glycogen & + & + & + & + & - & + \\
\hline Gentiobiose & + & + & + & + & - & + \\
\hline D-Turanose & + & + & + & - & - & - \\
\hline L-Fucose & - & - & + & - & - & - \\
\hline D-Arabitol & - & - & + & - & - & - \\
\hline Gluconate & - & - & - & - & - & + \\
\hline
\end{tabular}

${ }^{\star}$ Weakly positive. 
Table 2. Whole-cell fatty acid composition (\%) of the novel isolates and related species

Strains: 1, P. massiliensis $2301065^{\mathrm{T}} ; 2$, P. sanguinis $2301083^{\mathrm{T}} ; 3, P$. timonensis $2301032^{\mathrm{T}} ; 4$, P. illinoisensis DSM $11733^{\mathrm{T}} ; 5$, P. macerans DSM $24^{\mathrm{T}} ; 6$, P. pabuli DSM $3036^{\mathrm{T}} ; 7$, P. polymyxa DSM $36^{\mathrm{T}}$.

\begin{tabular}{|lrrrrrrr|}
\hline Fatty acid & $\mathbf{1}$ & $\mathbf{2}$ & $\mathbf{3}$ & $\mathbf{4}^{*}$ & $\mathbf{5}^{*}$ & $\mathbf{6}^{*}$ & $\mathbf{7}^{*}$ \\
\hline Straight-chain: & & & & & & & \\
$\mathrm{C}_{14: 0}$ & $2 \cdot 9$ & $0 \cdot 5$ & $1 \cdot 3$ & $2 \cdot 8$ & $6 \cdot 9$ & $3 \cdot 9$ & $1 \cdot 5$ \\
$\mathrm{C}_{15: 0}$ & $1 \cdot 6$ & $2 \cdot 8$ & $2 \cdot 0$ & $0 \cdot 7$ & $1 \cdot 0$ & $<0 \cdot 2$ & $0 \cdot 3$ \\
$\mathrm{C}_{16: 0}$ & $14 \cdot 1$ & $10 \cdot 1$ & $10 \cdot 6$ & $15 \cdot 1$ & $13 \cdot 2$ & $8 \cdot 3$ & $6 \cdot 5$ \\
Iso-branched: & & & & & & & \\
$\mathrm{C}_{14: 0}$ & $8 \cdot 0$ & $1 \cdot 7$ & $8 \cdot 2$ & $2 \cdot 1$ & $4 \cdot 8$ & $3 \cdot 1$ & $1 \cdot 9$ \\
$\mathrm{C}_{15: 0}$ & $5 \cdot 4$ & $6 \cdot 8$ & $10 \cdot 1$ & $5 \cdot 8$ & $7 \cdot 6$ & $11 \cdot 5$ & $7 \cdot 8$ \\
$\mathrm{C}_{16: 0}$ & $13 \cdot 6$ & $13 \cdot 4$ & $15 \cdot 5$ & $5 \cdot 5$ & $25 \cdot 7$ & $4 \cdot 4$ & $11 \cdot 3$ \\
$\mathrm{C}_{17: 0}$ & $1 \cdot 0$ & $5 \cdot 8$ & $1 \cdot 9$ & $3 \cdot 9$ & $6 \cdot 2$ & $2 \cdot 9$ & $4 \cdot 3$ \\
Anteiso-branched: & & & & & & & \\
$\mathrm{C}_{15: 0}$ & $42 \cdot 8$ & $44 \cdot 2$ & $43 \cdot 4$ & $51 \cdot 8$ & $24 \cdot 6$ & $53 \cdot 7$ & $55 \cdot 2$ \\
$\mathrm{C}_{17: 0}$ & $2 \cdot 9$ & $6 \cdot 8$ & $4 \cdot 0$ & $6 \cdot 2$ & $9 \cdot 0$ & $2 \cdot 4$ & $8 \cdot 8$ \\
\hline
\end{tabular}

${ }^{\star}$ Data from Elo et al. (2001).

are shown in Table 2 and compared with values that are available for closely related Paenibacillus species.

\section{DNA analysis}

Bacterial DNA was extracted by using the FastDNA kit (Bio101) as described by the manufacturer. PCR amplification of the 16S rRNA gene was done by using the universal primer pair fD1 and rp2 (Weisburg et al., 1991). PCR products were purified by using MultiScreen PCR (Millipore) and sequencing reactions were carried out by using a DNA sequencing kit (BigDye Terminator Cycle Sequencing v2.0 Ready Reactions; PE Biosystems) as described by the manufacturer. Sequence products were purified and electrophoresis was performed with a 3100 Genetic Analyzer (Applied Biosystems).

PCR products were cloned in pGEM-T Easy Vector (Promega) as described by the manufacturer. Ten clones were cultivated in LB medium (USB) overnight and plasmid purification was performed by using the Wizard Plus SV Minipreps DNA purification system (Promega). Determined sequences were compared with those available in GenBank by using the BLAST program through the NCBI server.

$16 \mathrm{~S}$ rRNA gene sequences were aligned by using the multisequence alignment program CLUSTALX (1.8). Phylogenetic relationships between representatives of the genus Paenibacillus were determined by using MEGA version 2.1 (Kumar et al., 2001). Distance matrices were determined following the assumptions described by Kimura (1980). These matrices were used to elaborate dendrograms by using the neighbour-joining method (Saitou \& Nei, 1987). A bootstrap analysis was performed to investigate the stability of the trees obtained. Bootstrap values were obtained for a consensus tree based on 100 randomly generated trees. Percentage similarities between 16S rRNA gene sequences were determined by using NALIGN in the PC/GENE software package (IntelliGenetics); similarities between existing Paenibacillus species and strains $2301065^{\mathrm{T}}, 2301032^{\mathrm{T}}$ and $2301083^{\mathrm{T}}$ were $87 \cdot 6-94 \cdot 4,88 \cdot 5-95 \cdot 4$ and $87 \cdot 5-96 \cdot 0 \%$, respectively.

It was impossible to determine the $3^{\prime}$ end of the $2301032^{\mathrm{T}}$ $16 \mathrm{~S}$ rRNA gene sequence. We therefore cloned the PCR product and found that several sequences were present. Direct sequencing was impossible, due to mutations and insertions. For this isolate, at least three different sequences were characterized. Recently, whole genomes of Bacillus species, which are phylogenetically close to the genus Paenibacillus, were sequenced. In the genomes of Bacillus subtilis, Bacillus cereus and Bacillus anthracis, respectively 10,13 and 11 genes that encode 16S rRNA were described (Kunst et al., 1997; Ivanova et al., 2003; Read et al., 2003). The high number of $16 \mathrm{~S}$ rRNA genes in the genomes of Paenibacillus species could explain the high diversity in the sequences of this gene for the same isolate. In fact, we observed this phenomenon for several representatives of the genus Paenibacillus (V. Roux, unpublished data).

Phylogenetic analysis, based on 16S rRNA gene sequence comparison, showed that isolate $2301065^{\mathrm{T}}$ could be grouped with Paenibacillus illinoisensis, but the bootstrap value at the node was low (33\%) (Fig. 1). Isolates $2301083^{\mathrm{T}}$ and $2301032^{\mathrm{T}}$ were grouped with Paenibacillus macerans in the same cluster. Bootstrap values at the different nodes were high $(82-100 \%)$. The $16 \mathrm{~S}$ rRNA gene sequences for strains $2301065^{\mathrm{T}}, 2301083^{\mathrm{T}}$ and $2301032^{\mathrm{T}}$ were found to contain the Paenibacillus-specific 22 bp sequence in variable region V5 (Ash et al., 1993).

Clinical signs of serious infection were not present in any of the three patients. It is, therefore, impossible to precisely determine the medical significance of the bacteria in blood-culture bottles. Skin or blood-bottle contamination, or asymptomatic bacteraemia in immunocompromised patients, are possible explanations. Antimicrobial sensitivity is presented in Table 3.

On the basis of the results described above, we propose that strains $2301065^{\mathrm{T}}, 2301083^{\mathrm{T}}$ and $2301032^{\mathrm{T}}$ represent novel species of the genus Paenibacillus, for which the names Paenibacillus massiliensis sp. nov., Paenibacillus sanguinis sp. nov. and Paenibacillus timonensis sp. nov., respectively, are proposed.

\section{Description of Paenibacillus massiliensis sp. nov.}

Paenibacillus massiliensis (mas.si.li.en'sis. L. masc. adj. massiliensis of Massilia, the old Greek and Roman name for Marseille, where the type strain was isolated).

Gram-positive, facultatively anaerobic rods $(0.5 \mu \mathrm{m}$ wide, $2 \cdot 0-4 \cdot 0 \mu \mathrm{m}$ long). Ellipsoidal endospores are formed in 


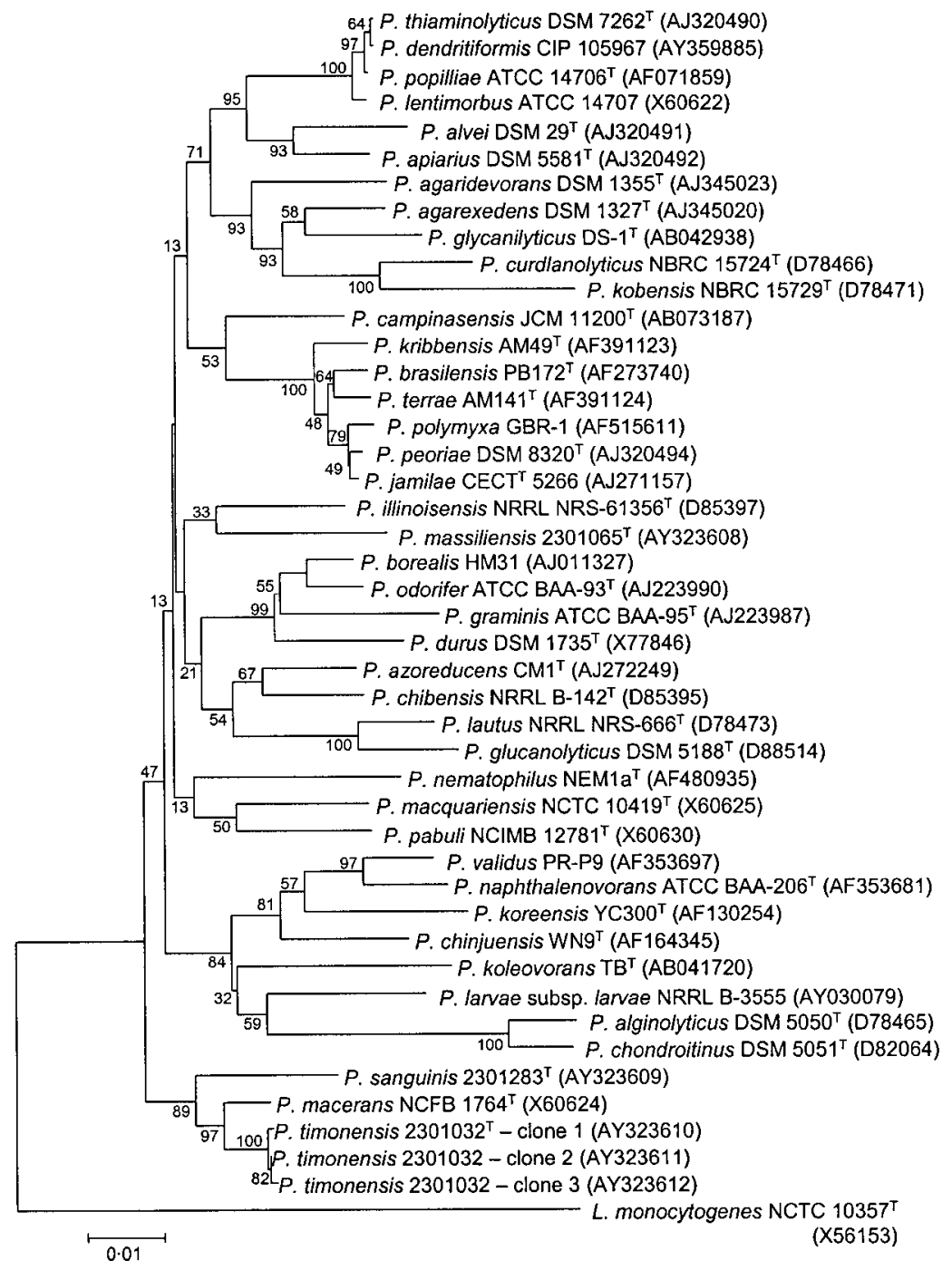

Fig. 1. Phylogenic tree of bacteria that belong to the genus Paenibacillus, inferred from comparison of $16 \mathrm{~S}$ rRNA gene sequences. Sequences (1440 nt) were aligned by using the multisequence alignment program CLUSTAL X (1.8). Phylogenetic relationships between representatives of the genus Paenibacillus were determined by using MEGA version 2.1. Distance matrices were determined by using Kimura's parameter. These matrices were used to elaborate dendrograms by using the neighbour-joining method. Numbers at nodes are proportions of 100 resamplings that support the topology shown. Listeria monocytogenes was used as the outgroup. Bar, 0.01 nucleotide changes per nucleotide position.

swollen sporangia. The organism grows on routine media and forms translucent, beige-coloured, flat colonies after incubation for $24 \mathrm{~h}$ at $30^{\circ} \mathrm{C}$. Bacteria are motile by means of peritrichous flagella. Catalase-positive, but oxidasenegative. Optimal growth occurs at $30-37^{\circ} \mathrm{C}$, but growth

Table 3. Antimicrobial susceptibility of the three novel Paenibacillus species

Strains: 1, P. massiliensis $2301065^{\mathrm{T}}$; 2, P. sanguinis $2301083^{\mathrm{T}} ; 3, P$. timonensis $2301032^{\mathrm{T}}$. S, Sensitive; R, resistant; I, intermediate.

\begin{tabular}{|llll|}
\hline Antimicrobial & $\mathbf{1}$ & $\mathbf{2}$ & $\mathbf{3}$ \\
\hline Amoxycillin & $\mathrm{S}$ & $\mathrm{S}$ & $\mathrm{S}$ \\
Gentamicin & $\mathrm{S}$ & $\mathrm{S}$ & $\mathrm{S}$ \\
Doxycycline & $\mathrm{S}$ & $\mathrm{S}$ & $\mathrm{S}$ \\
Erythromycin & $\mathrm{S}$ & $\mathrm{S}$ & $\mathrm{R}$ \\
Trimethoprim-sulfamethoxazole & $\mathrm{S}$ & $\mathrm{S}$ & $\mathrm{R}$ \\
Rifampicin & $\mathrm{S}$ & $\mathrm{S}$ & $\mathrm{I}$ \\
Vancomycin & $\mathrm{S}$ & $\mathrm{S}$ & $\mathrm{S}$ \\
\hline
\end{tabular}

at $50{ }^{\circ} \mathrm{C}$ is not inhibited. Growth occurs in the presence of $5 \%(\mathrm{w} / \mathrm{v}) \mathrm{NaCl}$. Nitrate is reduced, but gelatin is not liquefied. Acid is produced from glycerol, L-arabinose, ribose, galactose, glucose, fructose, mannose, mannitol, amygdalin, arbutin, aesculin, salicin, cellobiose, maltose, lactose, melibiose, sucrose, trehalose, raffinose, starch, glycogen and gentiobiose. Acid is not produced from erythritol, D-arabinose, D-xylose, L-xylose, adonitol, methyl $\beta$-D-xyloside, sorbose, rhamnose, dulcitol, inositol, sorbitol, methyl $\alpha$-D-mannoside, methyl $\alpha$-D-glucoside, $N$-acetylglucosamine, inulin, melezitose, xylitol, D-turanose, D-lyxose, D-tagatose, D-fucose, L-fucose, D-arabitol, L-arabitol, gluconate, 2-ketogluconate or 5-ketogluconate.

The type strain, which was isolated from blood culture, is strain $2301065^{\mathrm{T}}\left(=\mathrm{CIP} 107939^{\mathrm{T}}=\mathrm{CCUG} 48215^{\mathrm{T}}\right)$.

\section{Description of Paenibacillus sanguinis sp. nov.}

Paenibacillus sanguinis (san'gui.nis. L. masc. gen. n. sanguinis of blood, referring to the fact that the type strain was isolated from a blood sample). 
Gram-positive, facultatively anaerobic rods $(0.5 \mu \mathrm{m}$ wide, $2 \cdot 0-3 \cdot 0 \mu \mathrm{m}$ long). Ellipsoidal endospores are formed in swollen sporangia. Colonies are greyish, translucent, shiny, circular, $1 \mathrm{~mm}$ in diameter after incubation for $24 \mathrm{~h}$ at $30{ }^{\circ} \mathrm{C}$ and regularly shaped. Bacteria are motile by means of peritrichous flagella. Catalase- and oxidase-negative. Optimal growth occurs at $30-37^{\circ} \mathrm{C}$ and growth is inhibited at $50{ }^{\circ} \mathrm{C}$. Growth does not occur in the presence of $5 \%$ $(\mathrm{w} / \mathrm{v}) \mathrm{NaCl}$. Nitrate is not reduced and gelatin is not liquefied. Acid is produced from L-arabinose, D-xylose, methyl $\beta$-D-xyloside, galactose, fructose, mannitol, methyl $\alpha$-D-glucoside, $N$-acetylglucosamine, amygdalin, arbutin, aesculin, salicin, cellobiose, maltose, lactose, melibiose, sucrose, trehalose, inulin, melezitose and raffinose. Acid is not produced from glycerol, erythritol, D-arabinose, ribose, L-xylose, adonitol, glucose, mannose, sorbose, rhamnose, dulcitol, inositol, sorbitol, methyl $\alpha$-D-mannoside, starch, glycogen, xylitol, gentiobiose, D-turanose, D-lyxose, D-tagatose, D-fucose, L-fucose, D-arabitol, L-arabitol, gluconate, 2-ketogluconate or 5-ketogluconate.

The type strain, which was isolated from blood culture, is strain $2301083^{\mathrm{T}}\left(=\right.$ CIP $107938^{\mathrm{T}}=$ CCUG $\left.48214^{\mathrm{T}}\right)$.

\section{Description of Paenibacillus timonensis sp. nov.}

Paenibacillus timonensis (ti.mo.nen'sis. N.L. masc. adj. timonensis from the name Hôpital de la Timone, where the type strain was isolated).

Gram-positive, facultatively anaerobic rods $(0.5 \mu \mathrm{m}$ wide, $2 \cdot 0 \mu \mathrm{m}$ long). Ellipsoidal endospores are formed in swollen sporangia. Colonies are greyish, translucent, shiny, $1.5 \mathrm{~mm}$ in diameter, regularly shaped and low convex after incubation for $24 \mathrm{~h}$ at $30^{\circ} \mathrm{C}$. Bacteria are motile by means of peritrichous flagella. Catalase-positive, but oxidasenegative. Optimal growth occurs at $30-37^{\circ} \mathrm{C}$, but growth is not inhibited at $50^{\circ} \mathrm{C}$. Growth does not occur in the presence of $5 \%(\mathrm{w} / \mathrm{v}) \mathrm{NaCl}$. Nitrate is reduced weakly, but gelatin is not liquefied. Acid is produced from $\mathrm{L}$-arabinose, $\mathrm{D}$-xylose, galactose, glucose, fructose, mannose, methyl $\alpha$-Dglucoside, $\mathrm{N}$-acetylglucosamine, amygdalin, arbutin, aesculin, salicin, cellobiose, maltose, lactose, melibiose, trehalose, starch, glycogen, gentiobiose and gluconate. Acid is not produced from glycerol, erythritol, D-arabinose, ribose, D-xylose, L-xylose, adonitol, mannose, sorbose, rhamnose, dulcitol, inositol, mannitol, sorbitol, methyl $\alpha$-D-mannoside, sucrose, inulin, melezitose, raffinose, xylitol, D-turanose, D-lyxose, D-tagatose, D-fucose, L-fucose, D-arabitol, L-arabitol, 2-ketogluconate or 5-ketogluconate.

The type strain, which was isolated from blood culture, is strain $2301032^{\mathrm{T}}\left(=\right.$ CIP $108005^{\mathrm{T}}=$ CCUG $\left.48216^{\mathrm{T}}\right)$.

\section{Acknowledgements}

We are grateful to Nicolas Aldrovandi for his technical assistance in electronic microscopy, to Kent Molin (University of Göteborg, Sweden) for his technical assistance in cellular fatty acid composition and to Sanjeev Sahni for reviewing the manuscript.

\section{References}

Aguilera, M., Monteoliva-Sanchez, M., Suarez, A., Guerra, V., Lizama, C., Bennasar, A. \& Ramos-Cormenzana, A. (2001). Paenibacillus jamilae sp. nov., an exopolysaccharide-producing bacterium able to grow in olive-mill wastewater. Int J Syst Evol Microbiol 51, 1687-1692.

Antonello, A. \& Weinstein, G. W. (1989). Successful treatment of Bacillus alvei endophthalmis. Am J Ophthalmol 108, 454-455.

Ash, C., Priest, F. G. \& Collins, D. C. (1993). Molecular identification of rRNA group 3 bacilli (Ash, Farrow, Wallbanks and Collins) using a PCR probe test. Proposals for the creation of a new genus Paenibacillus. Antonie van Leeuwenhoek 64, 253-260.

Barrero, F., Galan, F., Marin, P., Garcia-Martos, P. \& Capote, F. J. (1996). Catheter associated infection by Bacillus macerans in a patient with acute leukemia. Enferm Infect Microbiol Clin 14, 628-629.

Berger, S. A. (1983). Pseudobacteremia due to contaminated alcohol swabs. J Clin Microbiol 18, 974-975.

Bert, F., Ouahes, O. \& Lambert-Zechovsky, N. (1995). Brain abscess due to Bacillus macerans following a penetrating periorbital injury. J Clin Microbiol 33, 1950-1953.

Centers for Disease Control \& Prevention (CDC) (1974). Recall of contaminated intravenous cannulae. Morb Mortal Wkly Rep 23, 57-58.

Dasman, Kajiyama, S., Kawasaki, H., Yagi, M., Seki, T., Fukasaki, E. \& Kobayashi, A. (2002). Paenibacillus glycanilyticus sp. nov., a novel species that degrades heteropolysaccharide produced by the corynebacterium Nostoc commune. Int J Syst Evol Microbiol 52, 1669-1674.

Elo, S., Suominen, I., Kämpfer, P., Juhanoja, J., SalkinojaSalonen, M. \& Haahtela, K. (2001). Paenibacillus borealis sp. nov., a nitrogen-fixing species isolated from spruce forest humus in Finland. Int J Syst Evol Microbiol 51, 535-545.

Heyndrickx, M., Vandemeulebroecke, K., Scheldeman, P., Kersters, K., De Vos, P., Logan, N. A., Aziz, A. M., Ali, N. \& Berkeley, R. C. W. (1996). A polyphasic reassessment of the genus Paenibacillus, reclassification of Bacillus lautus (Nakamura 1984) as Paenibacillus lautus comb. nov. and of Bacillus peoriae (Montefusco et al. 1993) as Paenibacillus peoriae comb. nov., and emended descriptions of P. lautus and of P. peoriae. Int J Syst Bacteriol 46, 988-1003.

Ivanova, N., Sorokin, A., Anderson, I. \& 20 other authors (2003). Genome sequence of Bacillus cereus and comparative analysis with Bacillus anthracis. Nature 423, 87-91.

Kimura, M. (1980). A simple method for estimating evolutionary rates of base substitutions through comparative studies of nucleotide sequences. J Mol Evol 16, 111-120.

Kumar, S., Tamura, K., Jakobsen, I. B. \& Nei, M. (2001). MEGA2: molecular evolutionary genetic analysis software. Bioinformatics $\mathbf{1 7}$, 1244-1245.

Kunst, F., Ogasawara, N., Moszer, I. \& 148 other authors (1997). The complete genome sequence of the gram-positive bacterium Bacillus subtilis. Nature 390, 249-256.

Meehan, C., Bjourson, A. J. \& McMullan, G. (2001). Paenibacillus azotreducens sp. nov., a synthetic azo dye decolorizing bacterium from industrial wastewater. Int J Syst Evol Microbiol 51, 1681-1685.

Noskin, G. A., Suriano, T., Collins, S., Sesler, S. \& Peterson, L. R. (2001). Clinical case study. Paenibacillus macerans pseudobacteremia resulting from contaminated blood culture bottles in a neonatal intensive care unit. Am J Infect Control 29, 126-129.

Read, T. D., Peterson, S. N., Tourasse, N. \& 49 other authors (2003). The genome sequence of Bacillus anthracis Ames and comparison to closely related bacteria. Nature 423, 81-86. 
Reboli, A. C., Bryan, C. S. \& Farrar, W. E. (1989). Bacteremia and infection of a hip prosthesis caused by Bacillus alvei. J Clin Microbiol 27, 1395-1396.

Saitou, N. \& Nei, M. (1987). The neighbor-joining method: a new method for reconstructing phylogenetic trees. Mol Biol Evol 4, 406-425.

Shida, O., Takagi, H., Kadowaki, K., Nakamura, L. K. \& Komagata, K. (1997). Emended description of Paenibacillus amycolatus and description of Paenibacillus illinoisensis sp. nov. and Paenibacillus chibensis sp. nov. Int J Syst Bacteriol 47, 299-306.

Takeda, M., Kamagata, Y., Shinmaru, S., Nishiyama, T. \& Koizumi, J. I. (2002). Paenibacillus koleovorans sp. nov., able to grow on the sheath of Sphaerotilus natans. Int J Syst Evol Microbiol 52, 1597-1601.

Teng, J. L. L., Woo, P. C. Y., Leung, K. W., Lau, S. K. P., Wong, M. K. M. \& Yuen, K. Y. (2003). Pseudobacteremia in a patient with neutropenic fever caused by a novel paenibacillus species: Paenibacillus hongkongensis sp. nov. J Clin Pathol 56, 29-35.

Weisburg, W. G., Barns, S. M., Pelletier, D. A. \& Lane, D. J. (1991). 16 S ribosomal DNA amplification for phylogenetic study. J Bacteriol 173, 697-703.

Woese, C. R. (1987). Bacterial evolution. Microbiol Rev 51, 221-271.

Yoon, J.-H., Oh, H.-M., Yoon, B.-D., Kang, K. H. \& Park, Y.-H. (2003). Paenibacillus kribbensis sp. nov. and Paenibacillus terrae sp. nov., bioflocculants for efficient harvesting of algal cells. Int J Syst Evol Microbiol 53, 295-301.

York, M. K. (1990). Bacillus species pseudobacteremia traced to contaminated gloves used in collection of blood from patients with acquired immunodeficiency syndrome. J Clin Microbiol 28, 2114-2116. 